\title{
Garota de Mitilene
}

\author{
ADÉLIA BEZERRA DE MENESES
}

Para o Dr. Campos da Paz.

"O seu modo de andar, despertando os desejos"

(Safo, Fragmento 5)

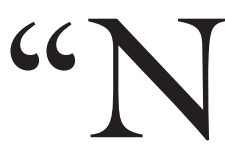

o CASO de 'Garota de Ipanema' o sucesso foi impressionante! Hoje a canção é universal. Aquela coisa de uma mulher bonita passar e o sujeito parar de fazer o que está fazendo só para olhar a moça é universal. [...] Este é um sentimento universal" - diz Tom Jobim em entrevista a Zuenir Ventura. ${ }^{1}$

O fato de o próprio Tom Jobim atribuir o sucesso extraordinário dessa canção feita em parceria com Vinicius (e que chegou a competir com os Beatles, ficando "entre as 10 músicas mais executadas nos Estados Unidos, quase no mesmo plano de algumas parcerias de Lennon \& McCartney, como Yesterday" (Souza, 1990, p.9-10)) por dizer respeito a um "universal", no entanto, tem que ser devidamente equacionado. Há que entender essa categoria, "universal", na sua plena dimensão: não é somente a temática que atinge as pessoas e define o impacto de uma obra, mas a sua "eficácia estética"2 a eficácia formal que, hegelianamente, faz passar do particular para o geral.

Mas vamos ao tema. Mesmo não sendo meu objetivo rastrear, na literatura, nas artes plásticas, no cinema ou na canção popular, o tema da "mulher que passa" (e a propósito: sabemos por depoimento de Vinicius de Moraes à revista Manchete (apud Cabral, 1987, p.153), em 1965, que inicialmente "Garota de Ipanema" chamava-se "Menina que passa") como algo que atravessa tempos e atravessa espaços, eu gostaria aqui de citar algumas incidências, à guisa de exemplos. Assim, o poema de Baudelaire "A une passante" ("... une femme passa, d'une main fastueuse / soulevant, balançant le feston et l'ourlet; / agile et noble, avec sa jambe de statue"); a canção "As vitrines", de Chico Buarque ("Passas sem ver teu vigia / catando a poesia / que entornas no chão"); e, ainda para ficarmos na MPB, a "Aquarela do Brasil”, de Ari Barroso: "Quero ver essa dona caminhando / pelos salões arrastando / o seu vestido rendado").

$\mathrm{Na}$ realidade, pretendo um único contraponto para tratar dessa "universalidade": efetivamente, se remontarmos séculos na lírica ocidental e recuarmos até a Grécia arcaica, encontraremos um surpreendente antecedente desse registro nos poemas (ou melhor, fragmentos) de Safo, que viveu em Mitilene, na costa oriental da ilha de Lesbos, no século 7 a.C. Efetivamente, no fragmento n.5, conhecido como "Ode a Anactória”, que diz que "A mais linda coisa sobre a terra ... é a pessoa que a gente quer”, na sequência, poucos versos adiante, há 
uma modulação inesperada do topos da "Garota de Ipanema": referindo-se a uma jovem chamada Anactória, o eu lírico diz preferir, aos carros e guerreiros em combate, "aquele modo de andar, que acorda os desejos". ${ }^{3}$ Cito as estrofes inicial e final - que nos interessarão mais de perto - desse poema, um dos menos lacunosos, por sinal:

É um batalhão de infantes - ou de cavaleiros

- dizem outros que é uma frota de negras naus

a mais linda coisa sobre a terra - para mim, é quem tu amas.

$[\ldots]$

agora, esta lembrança: Anactória

]daqui tão distante;

aquele modo de andar que acorda os desejos

e cambiantes brilhos, mais eu queria ver, no seu rosto, que soldados com panóplias e carros lídios

[em pleno combate]

]sua parte não pode esperar

]o humano [ ] mas desejá-la.

Aliás, não apenas relativamente ao tópico da mulher que caminha; há outras instigantes coincidências entre a lírica arcaica de Safo e o brasileiríssimo texto da canção de Jobim e Vinicius. Elenco o fundamental: os mesmos epítetos "bela" (linda) / "cheia de graça" endereçados à mulher; o dourado e suas ligações com o erotismo; a tristeza / solidão que irrompem (inesperadamente?) no meio da luminosidade de um poema que fala de amor. Isso tudo nos impele a um cotejo entre esses fragmentos de poemas de 2.700 anos atrás, da lírica ${ }^{4}$ grega, dessa primeira grande poeta à raiz da cultura ocidental, Safo, com o texto da canção de Vinicius e Jobim, de 1963. Todos, sob o denominador comum do pathos amoroso. Isso significaria - com as devidas precauções ante anacronismos na abordagem - uma atenção ao "diálogo cultural" que os autores de épocas tão afastadas empreendem entre si, levando em conta seus diferentes contextos culturais e as surpreendentes recorrências, com todos esses séculos de permeio.

A questão do tempo há de ser colocada, pois se estabelece inevitavelmente uma dialética entre as invariantes do sentimento amoroso e a historicização do afeto, uma vez que, como todo elemento constituidor do humano, a experiência erótica é modulada historicamente. Assim, não se poderia considerar o amor - e 
Vinicius de Moraes (1913-1980).

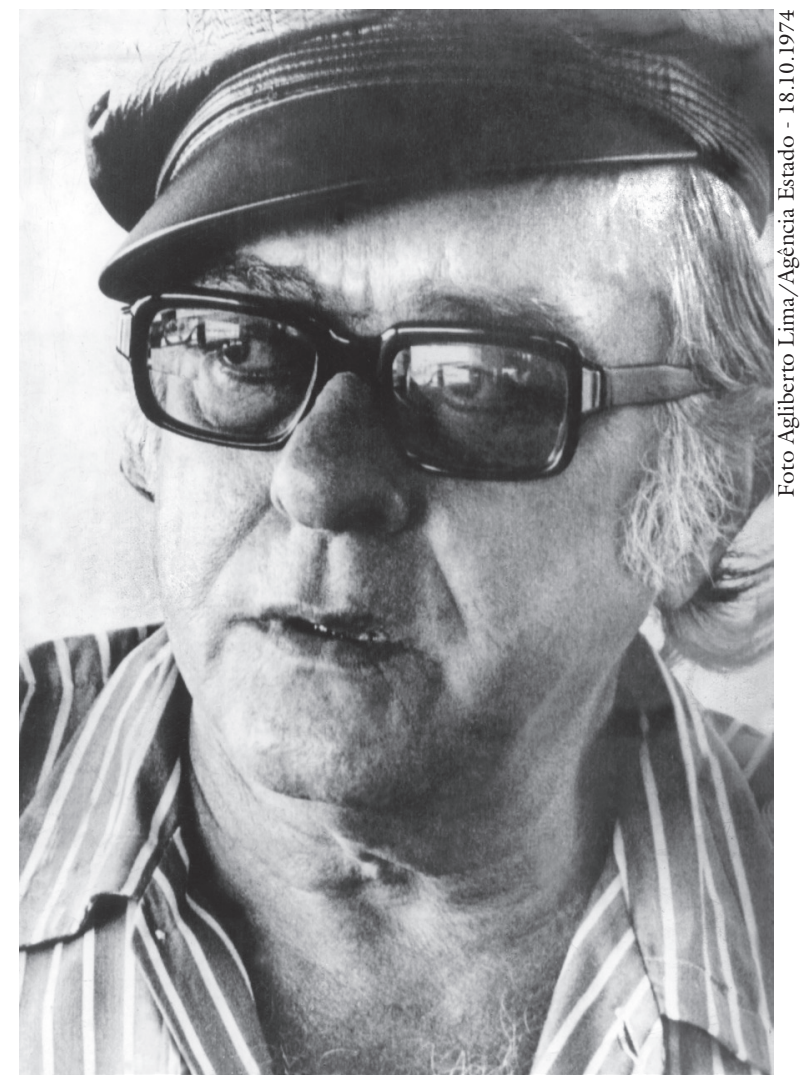

sua expressão - como algo de imutável ao longo dos séculos: tudo que é humano é marcado pelo tempo, não se vivencia um afeto hoje como na Antiguidade. No entanto, a essa historicidade contrapõe-se a evidência de semelhanças, de invariantes que atravessam séculos, que cruzam espaços. O sentimento amoroso, que é inexprimível a não ser pela poesia, não mudaria? Mas mesmo com todas as disposições para se respeitar a dimensão histórica, temos que nos dobrar, por vezes, à percepção inequívoca de uma invariante. Os estudiosos são unânimes em afirmar que a nossa concepção de amor data da lírica trovadoresca; no entanto, no caso dos poemas elencados, a lírica grega do século VII a.C. faz inequivocamente ressoar em nós algo que pertence à nossa experiência de brasileiros dos séculos XX-XXI...

Aliás, sob a égide de Walter Benjamin (1971, p.14), para quem "O problema não é apenas apresentar a obra literária em conexão com o seu tempo, mas sim tornar evidente, no tempo que a viu nascer, o tempo que a conhece e julga, ou seja, o nosso", eu diria que o grande significado desse contraponto é nos conhecermos a nós próprios, reconhecendo-nos nessa tentativa, que vem do fundo dos tempos, de dar forma verbal, de expressar por meio de palavras - que é a poesia - o que temos de mais pungente.

Uma observação prévia se impõe: uma vez que os poemas de Safo, salvo umas poucas exceções, nos chegaram cheios de lacunas, fragmentados, em cacos 
(literalmente, cacos de cerâmica), ou em farrapos de papiros, já se falou que seria preciso incorporar a fragmentação, a incompletude, a mutilação à nossa percepção dessa poesia. Jeanne Marie Gagnebin (2003) diz que, "paradoxalmente, é a mutilação que reforça o efeito de choque". Um poema é, séculos depois, ele próprio e tudo aquilo que o tempo aí agregou (ou desagregou). Nesse caso, são as incompletudes que, num paradoxo, se amalgamam ao corpo do texto, dando-lhe uma nova dimensão, apontando para o inconcluso, para o sugerido, para o lacunar, para o não definitivo - como é o conhecimento tateante que temos das coisas.

\section{Contraponto}

Impõe-se, então, um cotejo entre, de um lado, o texto da canção "Garota de Ipanema", e de outro, versos de Safo: sobretudo do fragmento número 5, conhecido como "Ode a Anactória":

Garota de Ipanema

Fragmentos de Safo

\begin{tabular}{|l|l|}
\hline $\begin{array}{l}\text { Olha que coisa mais linda } \\
\text { Mais cheia de graça }\end{array}$ & $\begin{array}{l}\text { Oh bela, } \\
\text { oh cheia de graça (Fr. 4 dos Epita- } \\
\text { lâmios) }\end{array}$ \\
\hline $\begin{array}{l}\text { É ela menina } \\
\text { Que vem e que passa } \\
\text { No doce balanço, a caminho do mar }\end{array}$ & $\begin{array}{l}\text { O seu modo de andar, despertando } \\
\text { os desejos (Fr. 5) }\end{array}$ \\
\hline Moça do corpo dourado & $\begin{array}{l}\text { mais áurea que o ouro (Fr. 45) } \\
\text {. e o brilho no seu rosto (Fr. 5) }\end{array}$ \\
\hline $\begin{array}{l}\text { Do sol de Ipanema } \\
\text { Ó seu balançado é mais que um poema } \\
\text { É a coisa mais linda que eu já vi passar }\end{array}$ & $\begin{array}{l}\text { a coisa mais linda na terra ... é para } \\
\text { mim, a pessoa que a gente } \\
\text { quer(Fr. 5) }\end{array}$ \\
\hline $\begin{array}{l}\text { Ah, por que estou tão sozinho } \\
\text { a hora passa e eu deitada estou, } \\
\text { sozinha (Fr. 31) }\end{array}$ \\
\hline $\begin{array}{l}\text { Ah, porque tudo é tão triste } \\
\text { Ah, a beleza que existe } \\
\text { A beleza que não é só minha } \\
\text { Que também passa sozinha }\end{array}$ & $\begin{array}{l}\text { os que são meu bem querer, esses } \\
\text { me trazem dores (Fr. 75) } \\
\text { Eros dociamargo (Fr. 19) }\end{array}$ \\
\hline $\begin{array}{l}\text { Ah, se ela soubesse } \\
\text { Que quando ela passa } \\
\text { O mundo inteirinho se enche de graça } \\
\text { E fica mais lindo } \\
\text { Por causa do amor [Bis] }\end{array}$ & $\begin{array}{l}\text { enquanto o desejo, de novo } \\
\text { à tua volta flutua (Fr. 56) }\end{array}$ \\
\hline
\end{tabular}


Como se vê, além do prestígio do andar da mulher desejada (a que retornarei adiante), ressaltam outros paralelos entre as duas produções líricas, surpreendentes invariantes para se dizer o encantamento, o desejo e suas vicissitudes. Aliás, repito: há que estabelecer uma dialética entre a historicidade e as invariantes. As expressões para caracterizar o ser desejado, a beleza e a graça da mulher são por vezes as mesmas, praticamente idênticas, tanto no poema de Vinicius/ Jobim quanto nas produções mais velhas de 27 séculos. Vamos a elas.

\section{ÓH BELA, ÓH CHEIA DE GRAÇA}

$\mathrm{Na}$ abertura da canção de Vinicius/Jobim, à invocação da beleza e da graça femininas "Olha que coisa mais linda, mais cheia de graça" poderia se contrapor um fragmento de Safo (fr. 4 dos Epitalâmios): "oh bela, (ou linda), ob cheia de graça". Ô kalê, ô charíessa": o original grego "kale" significa bela ou linda; e o termo chariessa, que vem do radical de charis, graça (da mesma etimologia de querido, caro, carinhoso, ou carne), quer dizer exatamente "cheia de graça". Beleza e graça: atributos femininos e da juventude, sendo a juventude assinalada, na canção de Jobim/Vinicius, mediante um substantivo em função adjetiva: "menina", em "ela menina". Impõe-se, no entanto assinalar as ressonâncias de sagrado e transcendente que o termo "graça" faz vibrar.

A importância desses epítetos ("linda" / "cheia de graça") se evidencia na canção brasileira pela sua tríplice repetição, uma pontuação distribuída no corpo do poema: no começo (v.1: "Olha que coisa mais linda / mais cheia de graça); no meio (v.9: "é a coisa mais linda que eu já vi passar"); e no fim (v.19 "O mundo inteirinho se enche de graça / E fica mais lindo...").

\section{MOÇA DO CORPO DOURADO}

Outra invariante é "moça de corpo dourado" - em que o dourado poderá receber, na canção de Jobim/Vinicius, uma conotação outra que a de um bronzeado de praia. Apesar de haver uma inequívoca alusão ao "sol de Ipanema" como responsável pelo corpo dourado, há também - no nível inconsciente uma possibilidade de associação a um topos comum na cultura grega: a ligação do dourado e do ouro a Afrodite, a deusa do amor. Uma associação que não se restringe à lírica de Safo, mas tem um tradição arraigada na literatura grega, onde Afrodite é dita "áurea”. É assim que ela aparece na Teogonia de Hesíodo, na Odisseia e no Hino Homérico a Afrodite (Ragusa, 2005, p.182ss). Observe-se que não no sentido de "adornada com ouro", mas no de que ela própria é reluzente. Deriva daí o topos do "brilho" ligado a Afrodite, uma ênfase na luminosidade da deusa ou daqueles que estão por ela tocados. Ouro e brilho são elementos ligados à sedução erótica; e Afrodite é a grande sedutora, a que homens e deuses sucumbem. Diga-se, no entanto, que essa ligação do amor com o ouro é uma tradição poética da Antiguidade não apenas grega, mas também semítica - ou melhor, oriental (plausível sobretudo levando-se em conta a proximidade de Lesbos com a costa oriental, especialmente a Lídia). Não por acaso o Amado do "Cântico dos Cânticos" bíblico, numa de suas descrições, é de ouro. ${ }^{5}$ 
Voltemos à garota de Ipanema de Jobim e Vinicius. Ela parece concentrar em si - para irradiá-la - uma beleza resplandecente e a força luminosa do sol. E se importa estudar o que para uma determinada cultura significa tal imagem - e é isso o objeto de uma História do Imaginário -, importa também verificar as associações que se universalizam porque se efetivam por analogia. E analogia, já dizia o mestre Aristóteles, é "associação do semelhante com o semelhante". Em qualquer cultura, o "brilho" (seja dos olhos, seja do sorriso, seja da face) está ligado a um estado de paixão. "Mais áurea que o ouro", diz o fragmento n.45 de Safo, sem um referente que possa ser identificado, abrindo todo um campo de especulações.

\section{TRISTEZA E SOLIDÃO}

$\mathrm{Na}$ terceira estrofe de "Garota de Ipanema", inesperadamente, em meio ao esplendor do corpo dourado que passa, irrompem a tristeza e a solidão: " $A h$, porque estou tão sozinho / "Ah porque tudo é tão triste"; "A beleza que [...] também passa sozinha" - como que indiciando a carência e a falta indissociáveis da existência humana, como um ingrediente da lírica amorosa de todos os tempos. O poema sofre aqui uma inflexão meditativa. Amor rima com dor, como já tinha sido registrado por Safo, que em muitas passagens da sua obra apresenta imagens recorrentes do caráter contraditório do amor: "Eros dociamargo" (Fr.19); "Os que são meu bem querer, esses me trazem dores" (Fr. 75). Em "Garota de Ipanema", das quatro estrofes que compõem a canção, uma inteirinha reitera a tristeza e a solidão do eu lírico. Como a que Safo, no fragmento 31, expressa numa tocante simplicidade, em versos que conjugam o "estar sozinha" (no original: ego de mona - mas eu só) com a passagem implacável do tempo, um tempo mensurado pelo movimento dos astros:

A lua já se pôs, as Plêiades também;

É meia noite;

A hora passa, e eu deitada estou, sozinha.

Na já referida entrevista à revista Manchete, em 1965, Vinicius de Morais dá um depoimento, falando da menina frequentadora da praia de Ipanema que lhes teria servido de inspiração; e, secundariamente, aponta uma razão para a "tristeza":

Ela foi e é para nós o paradigma do broto carioca: a moça dourada, misto de flor e sereia, cheia de luz e de graça, mas cuja visão é também triste, pois carrega consigo o caminho do mar e o sentimento da mocidades que passa, da beleza que não é só nossa - é um dom da vida em seu lindo e melancólico fluir e refluir constante. (apud Cabral, 1987, p.153)

Continuemos o contraponto: o final da canção "Garota de Ipanema" deixa a melancolia e volta a falar de graça e beleza - ou melhor, de uma beleza que vem do amor; ou do contágio que o amor provoca, espalhando-se pelo entorno: 
"O mundo inteirinho se enche de graça/ E fica mais lindo/ Por causa do amor." Vejamos Safo: "Enquanto o desejo, de novo, / à tua volta flutua" (Fr.56.). Estamos em pleno universo da analogia; e será inevitável que, com o filósofo Gianbatista Vico (1979), a gente não veja aí uma “transposição do corpo humano e das humanas paixões" sobre a realidade circundante. Não por acaso, nessa mesma entrevista à revista Manchete, diz Vinicius sobre a menina de Ipanema: “O ar ficava mais volátil como para facilitar-lhe o divino balanço do andar" (apud Cabral, 1987, p.153).

\section{O SEU BALANÇADO É MAIS QUE UM POEMA}

Voltemos ao topos do andar da mulher desejada, que marca tão vincadamente a canção de Vinicius/Jobim, tanto imagética quanto ritmicamente. A sedução provocada pelo modo de caminhar da mulher amada tem uma de suas comprovações no romance do escritor alemão Wilhelm Jensen, Gradiva, que se tornou conhecido pelo famoso estudo que lhe dedicou Freud (1976), garantindo posteridade psicanalítica a essa obra. Com efeito, tendo na sua "fortuna crítica" um estudo com a genialidade do mestre da psicanálise, essa obra de ficção tornou-se uma contribuição - nos termos do próprio Freud - para a "psicologia do amor”. Mas como se verá, trata-se de um romance bastante interessante e, que não por acaso, suscitou o interesse freudiano.

Publicado em 1903, e apresentado a Freud por Jung, ${ }^{6}$ esse romance conta a história de um jovem arqueólogo alemão, Norbert Hanold, que descobrira num museu de Antiguidades de Roma uma escultura em mármore, pela qual fica absolutamente fascinado. Ele manda fazer uma cópia em gesso que coloca em seu gabinete de trabalho, ${ }^{7}$ numa cidade universitária da Alemanha. Trata-se de um baixo-relevo que reproduz a imagem de uma jovem mulher flagrada em movimento, e cujas vestes esvoaçantes descobrem os pés surpreendidos em plena caminhada: um deles repousa no chão, e o outro está já flexionado para o passo seguinte, ficando a planta do pé quase que num ângulo de 90 graus em relação ao chão. As pregas da túnica mostram a ondulação do caminhar. É a imagem de uma mulher em movimento, e Norbert Hanold chama a figura do relevo de "Gradiva", "aquela que caminha", ou "aquela que avança".

Aliás, "Gradiva” é uma transposição para o feminino de "Gradivus", um dos epítetos de Marte, o deus da Guerra, "Mars Gradivus", isto é, "Marte que avança". Além de dar-lhe um nome, o jovem arqueólogo começa a inventar uma história de vida para a mulher esculpida, imaginando-a em Pompeia, soterrada pela erupção do Vesúvio, mais de 1800 anos atrás. Resolve num impulso viajar para Pompeia, onde, em visita às ruínas remanescentes da erupção vulcão, encontra, também em viagem de turismo, Zoé Bertgang, que tinha sido na infância sua amiga de brincadeiras, mas de quem ele se esquecera e que atualmente era sua vizinha no bairro em que morava. Mas, mergulhado nos estudos de arqueologia, para onde desviara todo seu interesse (toda sua libido, dirá Freud), ele nem a notava. No entanto, Zoé Bertgang tinha uma peculiaridade: ao andar, 


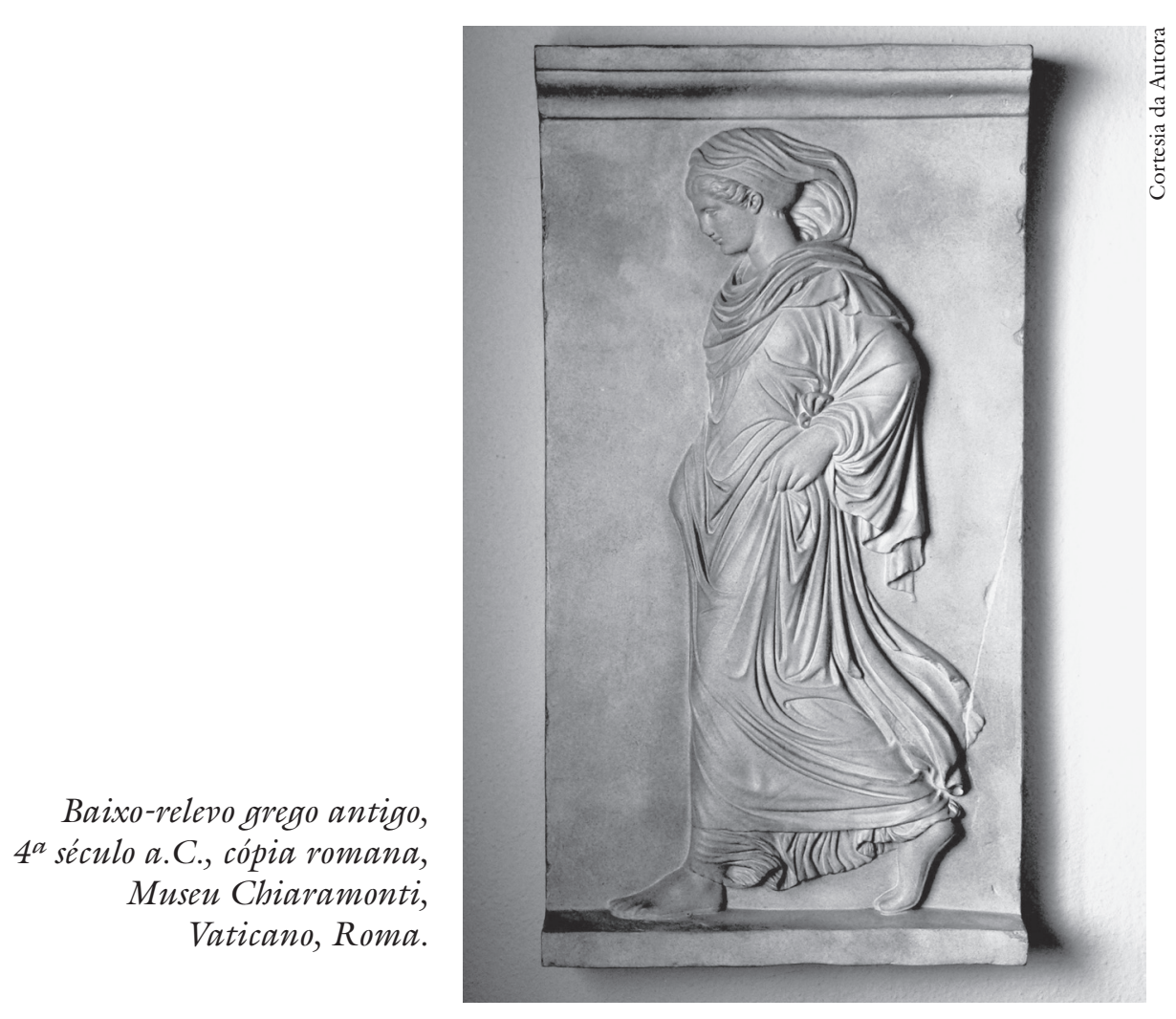

enquanto um de seus pés se firmava horizontalmente no chão, o outro assumia uma posição de um ângulo quase reto em relação ao solo. $\mathrm{O}$ jovem arqueólogo interpreta o surgimento da moça, em meio às pedras de Pompeia, naquele contexto, como uma aparição da Gradiva do seu baixo-relevo, rediviva; interpelando-a em grego, depois em latim, obtém uma resposta em alemão. De início intrigadíssima, logo Zoé se aperceberá do delírio do seu amigo de infância. Ela entra no seu jogo - literalmente, entra no seu delírio - e, com inteligência, sensibilidade (e contratransferência) vai conseguir conduzi-lo para um religamento com a realidade. Com sua ajuda, Norbert Hanold vai chegar finalmente a ver na Gradiva soterrada esse amor de sua infância. E seus sentimentos se deslocarão da mulher de mármore para a moça viva, Zoé (que em grego quer dizer: vida). E a propósito: não por acaso, o sobrenome da moça, Bertgang, como refere numa determinada passagem do romance a própria personagem do jovem arqueólogo (versado não somente nas línguas clássicas mas na etimologia anglo-germânica), tem o mesmo significado que Gradiva, e quer dizer "alguém que brilha ao caminhar" (Jensen, 1949, p.115). Transcrevo uma nota de rodapé do texto de Freud (1976, nota 1, p.45), publicado pela Imago, que esclarece: "A raiz alemã 'bert' ou 'brecht' corresponde ao inglês 'bright' (brilho); do mesmo modo, 'gang' corresponde a 'go' - na Escócia, 'gang' (ir andar)".

Assim reencontramos, na jovem que caminha com graça e cujo andar seduz, a presença do brilho que esplende. Vemos aqui também, como nos frag- 
mentos de Safo, a questão do luminoso "dourado" de que se reveste o objeto da paixão. E que nos remete evidentemente à "moça de corpo dourado" de Ipanema e ao "brilho do rosto" da moça de Mitilene (tocadas certamente pela "áurea Afrodite"). O sobrenome da protagonista, a Gradiva rediviva, Zoé Bertgang, significa "aquela que esplende ao caminhar".

\section{O DOCE BALANCSO E O MAR}

Diz Vinicius, em entrevista à Manchete:

E lá ia ela toda linda, a garota de Ipanema, desenvolvendo no percurso a geometria espacial do seu balanceio quase samba, e cuja fórmula teria escapado aos egípcios, teria escapado ao próprio Einstein; seria preciso um Antonio Carlos Jobim para pedir ao piano, em grande e religiosa intimidade, a revelação do seu segredo. (apud Cabral, 1987, p.153)

Efetivamente, "O seu balançado é mais que um poema": é extremamente interessante essa vinculação que se faz entre o "balanceio" da mulher e o poema - na realidade, algo que alude a um elemento que frequenta tanto a canção de Jobim/Vinicius quanto o andar feminino: o ritmo. E significativamente o ritmo tem, entranhado na sua própria etimologia, o movimento das ondas do mar. De fato, "ritmo", do grego rythmós, significa o movimento regular das ondas, movimento das vagas. Importa saber que esse substantivo grego tem a mesma raiz de reo (= correr), um verbo aferido à natureza do curso da água: passar, fluir. “Onda" é a água que vai, mas volta; fluxo e refluxo. Daí: movimento mensurado; cadência - ou, numa expressão dos compositores brasileiros: o balançado "que vem e que passa / no doce balanço / a caminho do mar". O mar não é apenas a meta dos passos da menina, mas o mar dá o compasso.

Ainda uma observação: quase como numa brincadeira, é inevitável que se faça alusão a um dado que talvez não seja irrelevante, quer se trate da "Garota de Ipanema”, quer da "Ode a Anactória” e que diz respeito ao espaço de ambas produções: a proximidade física do mar - seja na orla da cidade do Rio de Janeiro, com suas praias banhadas pelo Atlântico, seja na costa da cidade de Mitilene, da Ilha de Lesbos, no Mar Egeu. Não estou querendo comparar uma praia tropical do Atlântico com um costão de uma ilha do Mar Egeu, mas apenas apontar a presença do mar, da maré e seus ritmos.

Em seu ensaio no Songbook de Jobim, Tarik de Souza (1990, p.10) diz:

No sinuoso desenho dos passos da Garota de Ipanema, em seu doce balanço a caminho do mar, o musicólogo Almir Chediak flagrou um exemplar de "música figurativa". O layout melódico da partitura reporta-se ao enunciado poético da célebre parceria com Vinicius.

E na sequência, ele cita textualmente o que, nos seus termos, "ensina" Almir Chediak (apud Souza, 1990, p.10), musicólogo e, não por acaso, idealizador do Songbook de Jobim:

Na primeira parte, a música delineia uma onda que vai se enrolando até arrebentar na praia, através de um clichê de seis notas que se repetem quatro vezes. 
Já na segunda parte, a música vai subindo de tom para conduzir a um clímax, à crista da onda, com o prolongamento das notas iniciais e finais de cada frase, em séries de acordes com oito notas que se repetem em alturas diferentes.

E ilustrando a citação, o Songbook de Jobim estampa o gráfico ${ }^{9}$ de Almir Chediak:

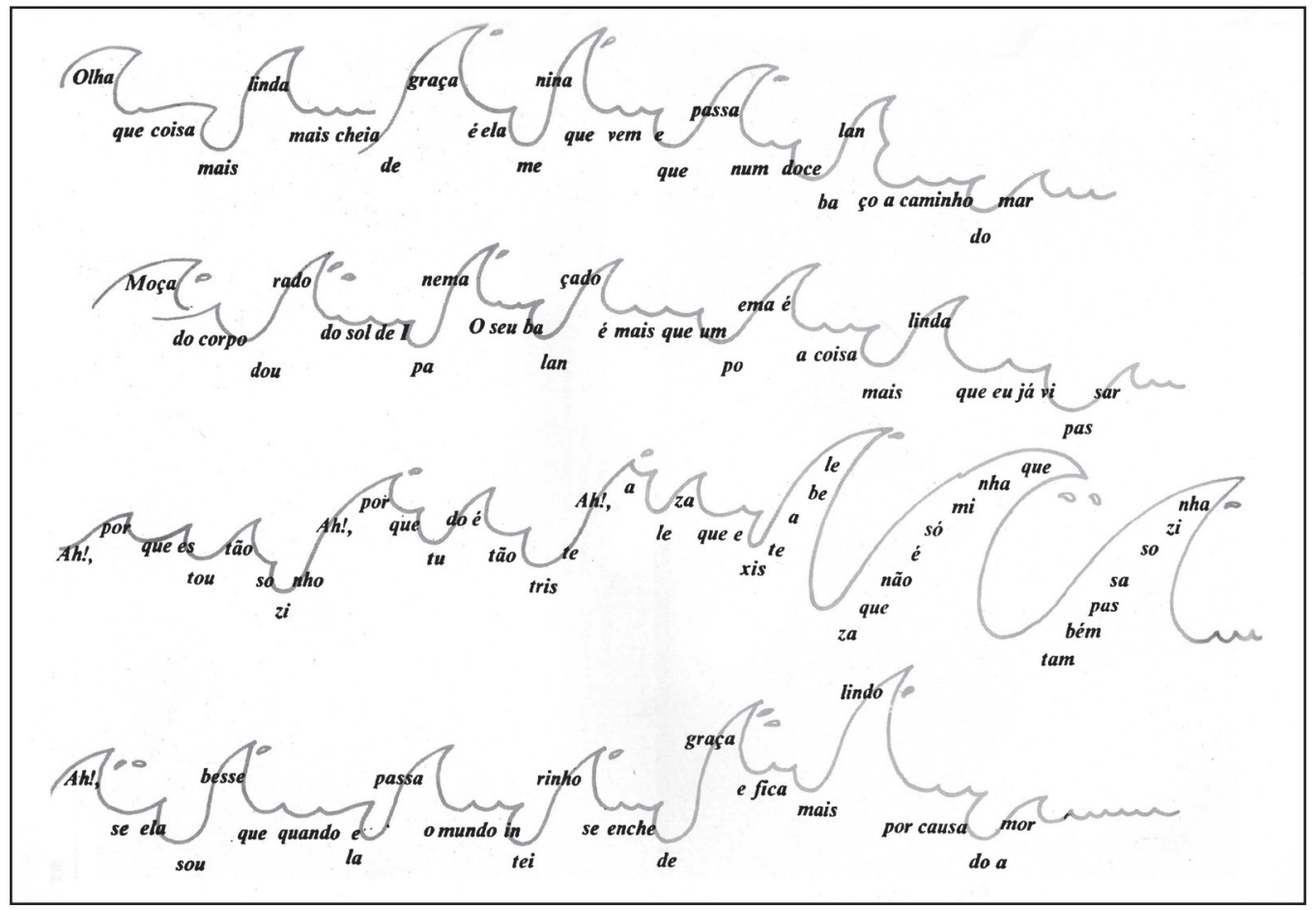

Efetivamente, a onda, o passo ondulante, o doce balanço, o ritmo, o tema: tudo converge. Eficácia formal / eficácia estética: atingimos um universal. "O seu balançado é mais que um poema": não somente o poema da garota de Ipanema, mas o de outras muitas garotas, ao longo dos tempos e dos espaços: também o da garota de Mitilene. E o da garota Zoé Bertgang.

\section{Notas}

1 Tom Jobim, entrevistado por Zuenir Ventura, em Martins e Abrantes (1993, p.177).

$2 \mathrm{O}$ termo é de Antonio Candido.

3 Utilizarei as traduções de Safo feitas por Joaquim Brasil (1971 e 2003)

4 Ou "mélica", como denominam atualmente os helenistas (cf. Ragusa, 2005).

5 Cf a descrição que a Amada faz do Amado: "Sua cabeça é ouro puro, uma copa de palmeira seus cabelos" [...]; Seus braços são torneados em ouro / incrustado com pedras de Társis.[...] Suas pernas, colunas de mármore/ firmadas em base de ouro puro. (“Cântico dos Cânticos”, 5,$11 ; 14 ; 15$ ). 
6 Como conta a "Nota do Editor inglês" do texto "Delírios e sonhos na Gradiva de Jensen" (Freud, 1976, p.14).

7 É interessante observar-se que essa escultura atraiu tanto a atenção do próprio Freud, que ele tinha uma réplica em seu consultório em Viena. O exemplar de Freud está hoje numa parede de sua sala de estudos da casa onde morou em Londres, atual Museu Freud.

8 Aqui também, uma aproximação, como em Safo, entre Amor e Guerra.

9 Tal "gráfico" pertence ao mesmo universo daquilo que Villa Lobos criou sob a denominação de "Melodia das Montanhas", quando, influenciado por E. Varèse, o compositor brasileiro buscou uma forma de criação de melodia a partir do relevo geográfico significativo de uma região. É assim que ele procedeu ao decalque do contorno do maciço do Pão de Açúcar sobre uma folha de papel quadriculado, estipulando convencionalmente o valor das figuras e alturas dos sons. Daí obteve o desenho melódico da fotografia da paisagem em questão. [Cf. Kater, 1984, p.102-5. Agradeço a indicação dessa referência a Maria Luiza Camargo.] No entanto, cabe aqui uma discriminação entre a visão estática da montanha e a percepção do movimento do mar, que o andar mimetiza.

\section{Referências}

BENJAMIN, W. Histoire littéraire et science de la literature. In: Poésie et Revolution. Paris: Denoel, 1971.

BRASIL, J. Eros, tecelão de mitos. A poesia de Safo de Lesbos. São Paulo: Estação Liberdade, 1971. . Safo de Lesbos. Poemas e fragmentos. São Paulo: Iluminuras, 2003.

CABRAL, S. (Org.) Tom Jobim. São Paulo: Companhia Brasileira de Projetos e Obras - CBPO; Rio de Janeiro: Sabiá, Produções Artísticas, 1987.

FREUD, S. Delírios e sonhos na Gradiva de Jensen. In: Obras psicológicas completas. Rio de Janeiro: Imago, 1976. v.IX.

GAGNEBIN, J. M. Um rosto iluminado. Prefácio. In: BRASIL, J. Safo de Lesbos. Poemas e fragmentos. São Paulo: Iluminuras, 2003.

JENSEN. Gradiva. In: FREUD, S. Délire et rêves dans la Gradiva de Jensen. Traduit de l'allemand par Marie Bonaparte, et precédé du texte de Jensen traduit par E. Zak et G. Sadoul. Paris: NRF; Gallimard, 1949.

KATER, C. Villa Lobos e a "Melodia das Montanhas". Contribuição à revisão crítica da pedagogia musical brasileira. Latin American Music Review, v.V, p 102-5, 1984.

MARTINS, M.; ABRANTES, P. R. (Org.) Três Antonios e um Jobim - Histórias de uma geração. Rio de Janeiro: Relume Dumará, 1993.

RAGUSA, G. Fragmentos de uma Deusa. A representação de Afrodite na Lírica de Safo. Campinas: Editora da Unicamp, 2005.

SOUZA, T. de. As marés do maestro modernista. In: CHEDIAK, A. Songbook Tom Jobim - N.3. Rio de janeiro: Lumiar Editora,1990.

VICO, G. Princípios de uma Ciência Nova. 2.ed. Trad. Antonio Lázaro de Almeida Prado. São Paulo: Abril Cultural, 1979. 
RESUMO - A proposta é uma abordagem de "Garota de Ipanema" de Jobim e Vinicius e de um poema de Safo, "Ode a Anactória” (século VII a.C.), que abriga um verso que diz, literalmente: "Esse modo de andar que desperta o desejo". E aí, aproveitando a deixa, desenvolvo um cotejo entre outros fragmentos de Safo e essa canção paradigmática da MPB, datada de 1962. Trata-se de um contraponto com 27 séculos de permeio e que - por maior que seja o cuidado em respeitar a historicidade do afeto (e não cometer anacronismos) - revela surpreendentes invariantes. Mas entre Safo e Jobim/Vinicius há Freud, ou melhor, Jensen, com a sua Gradiva - que tematiza, exatamente, o andar da mulher desejada. Por sua vez, o musicólogo Almir Chediak vê um paralelo entre o desenho melódico da partitura de "Garota de Ipanema" e as ondas do mar, no seu movimento de fluir e refluir; e no gráfico apresentado, de fato, delineia-se esse ritmo iconizado. Efetivamente, a onda, o passo ondulante, o ritmo, o tema, "o doce balanço, caminho do mar": tudo converge nessa brasileiríssima canção, que patenteia, no entanto, tão instigantes recorrências com a lírica grega arcaica.

PALAVRAS-CHAVE: Garota de Ipanema, Jobim e Vinicius, Fragmentos de Safo, Gradiva de Jensen - Freud, Cotejo MPB / Lírica grega arcaica.

ABSTRACT - This essay examines the song "The Girl from Ipanema” by Jobim \& Vinicius in tandem with a poem by Sappho, "Ode to Anactoria" ( $7^{\text {th }}$ century b.C.), which contains a verse that says, literally: "This way of walking that awakens desire". Taking the cue, I establish comparisons between other fragments by Sappho and this paradigmatic Brazilian song, dated 1962. Even with the greatest respect for the historicity of affection (to avoid anachronisms), we nevertheless find surprising invariances in their counterpoint, regardless of the 27-century hiatus. Between Sappho and Jobim/Vinicius, however, there is Freud - or rather, Jensen and his Gradiva, which speaks, precisely, of the walk of the desired woman. On the other hand, musicologist Almir Chediak sees a parallel between the melodic design of the score of "The Girl from Ipanema" and the ebb and flow of the waves of the sea. In the accompanying graph, we can indeed discern this iconic rhythm. The waves, the undulating gait, the rhythm, the basic theme, "O balanço a caminho do mar" [i.e., the girl's cool swinging and gentle swaying as she walks to the sea] all converge in this most Brazilian of songs, in which we nevertheless find a very alluring recurrence of archaic Greek lyric poetry.

KErWORDS: The Girl from Ipanema, Jobim/Vinicius, Fragments from Sappho, Jensen's Gradiva - Freud, Comparison between Brazilian popular music and archaic Greek lyricism.

Adélia Bezerra de Meneses é doutora em Teoria Literária e Literatura Comparada pela USP. Foi docente de Literatura Brasileira no Leitorado de Romanística da Technische Universität de Berlim, professora de Teoria Literária e Literatura Comparada na USP e na Unicamp, onde se aposentou. @-adeliabm@terra.com.br

Recebido em 12.7.2012 e aceito em 10.8.2012. 